\title{
Contribution to the Measurement of Organizational Performance based on A Multi-Agent Approach
}

\author{
Ansar Daghouri, Khalifa Mansouri, Mohammed Qbadou \\ Laboratory : Signals, Distributed Systems and Artificial Intelligence (SSDIA) \\ ENSET of Mohammedia, Université Hassan II of Casablanca \\ dagh.ansar@gmail.com,khmansouri@hotmail.com, qbmedn7@gmail.com
}

\begin{abstract}
This research focuses on evaluating and analyzing the organizational performance of a risk management unit within banks. The main proposal is to analyze and simulate the process of risk management based on decision support system and artificial intelligence. This is why this paper uses the systemic thinking and simulation tool. We finally propose a multi-agent model showing nine autonomous agents communicating with each other to simulate a risk. This model provides both a tool to simulate the risk and a way to modify the organizational structure of the risk management unit to improve the performance of bank.

Keywords : Organizational performance; Decision Support Systems; Artificial Intelligence; Systemic thinking.

\section{Introduction}

The business of banking is the ability to manage risks. These risks are unexpectedly recurrent in terms of their number and frequency. Good risk management is affected by the structure and the internal organization of the unit itself. This work presents an approach which aims at building a decision support system dedicated to the analysis of the organizational performance of a risk management unit. It is based on the systemic approach through the following steps: the observation to delimit the system and its interactions, the static modeling to describe the system in a formal way according to certain standards, the identification of the indicators in order to focus on the weak-spots and the strength of the unit, and the dynamic modeling by using multi-agent system in order to simulate the technical subtleties of the studied system.
\end{abstract}

\section{Position of the problem}

\subsection{Bank risks}

Risks refer to a well-identified threat associated to the occurrence of an event or series of events which are perfectly descriptive, and it is not known whether they will occur once again or not but they are still likely to occur in an exposing situation[1].

The bank like any other organization faces risky conditions. The risks which a bankmay face are variable and both their nature and extent are relative. However, in addition to the diversity of types of risks and the narrow or extended scope of each type, they are classified as follows: 


\subsection{Typology of bank risks [2]:}

\section{Credit risk}

It is the risk in which financial losses are due to the clients' or counterparties' inability to honor their financial commitments. In other words, it is the risk that the borrower will not repay his debt at a certain deadline.

\section{Market risk}

Market risk is when the bank undergoes financial losses as a result of changes in stock prices, currency or interest rates.

\section{Operational risk}

It is linked to the risk of loss which results from maladaptation or imputable failure due to internal procedures, personnel and systems or external events.

\section{Risk of non-conformity}

It is the risk of penalty or financial loss which arises from non-compliance with the financial regulations of banks or their internal rules.

\section{Liquidity risk}

This is a risk for which the bank may not be able to meet its obligations as they fall due. It results from a bank's inability to meet a reduction in its liabilities or to finance an increase in its assets.

\section{Interest rate risk}

Interest rate risk is identified as the negative impact of the adverse changes in interest rates on the financial position of the bank. Interest rate risk concerns both the interest rate positions taken in trading halls and the exposure to thetransformation risk that is inherent in banking by definition.

\section{Strategic risk}

It is a risk which is inherent in the chosen strategy or which results from the inability to implement this strategy. A strategic failure can be very serious because the committed resources become worthless and hence the losses become very significant.

\section{Reputation risk}

It arises from a negative perception by customers, counterparties, shareholders or investors, which may adversely affect the ability of the bank to maintain business relationships and the continuity of access to sources of finances.

\subsection{Risk management}

Risk management in banks is a topical issue from which many countries suffer (United States, Japan, Great Britain, France...). This phenomenon is the result of economic problems.

A few years ago, Morocco also got close to falling into financial instability.Thanks to the government's initiative, banks were able to avoid this crisis before it could create more dangerous impacts.

These financial crises, which have attacked the Moroccan market in particular and the international one on a large scale, have clearly highlighted the weaknesses in risk management in the banking sector. [3] 
Ansar Daghouri, Khalifa Mansouri, Mohammed Qbadou; Contribution to the Measurement of Organizational Performance based on A Multi-Agent Approach. Transactions on Machine Learning and Artificial Intelligence, Vol 5 No 4 August (2017); pp: 102-111

Traditional management based on simply the compliance with the prudential rules has proved ineffective because of lacking the involvement of management and the board of directors in banking organizationcontrol.

Under these conditions, it becomes clear that a global approach to banking risk management is no longer sufficient, hence the need for the involvement of management and the board of directors in choosing the most appropriate tools .

\section{Banks Vs. risk management}

Banking risk management corresponds to all the techniques and tools put forward by banks to measure and monitor the risks which they may face.

The banking institutions are engaged with different degrees of involvement in the implementation of management tools allowing early monitoring of the different types of risks.

The leaders must have procedures and tools for managing the various risks; this management brings together three fundamental elements:

Risk assessment: it is a continuous process with three stages namely the rigorous analysis and the quantification of risks, the determination of the level of risk tolerated by the bank, and the comparison of the level of risk tolerance with the scale of its assessment;

Risk management and control: following the assessment of risks and the level of risk tolerance, the bank's management must take steps to manage and control the risks such as the implementation of policies and the security measures;

Continuous risk monitoring: this is the most important step in the management process since banking activities are rapidly evolving at the rate of innovation. They use new technological tools such as the Internet hence the need for tests and audits (internal and external).

\subsection{Performance and measurement tools}

\section{Performance}

The term of performance is widely used in the field of management sciences, according to Bourguignon , in spite of the fact that there is no single and unanimous definition of this term. Its etymological origins signify the accomplishment of a task in order to evoke afterwards the exploit and the success.

Based on the state of the art, performance is defined as the combination of effectiveness, which is the ability to achieve the objectives and the efficiency which is the relationship between the means and the efforts being made.

Performance can not be defined as a simple concept because it is a notion that encompasses several dimensions. In this paper, we are interested in organizational performance which is defined as the measures which are directly related to the organizational structure and not on its possible social or economic consequences. 
In fact, the performance of an organization is measured by performance criteria; there is no single criterion or an exhaustive list covering the various performance criteria.

\section{Method and tool for measuring performance}

«Performance measurement describes and implements the strategy, the monitoring of organization, decision-making and improving coordination» [4].

The state of the art has not made it possible to distinguish a single and a common method for the measurement of organizational performance.

However to construct the indicators for performance measurement, there are different currents of thought[5].

These different currents make it possible to construct the organizational indicators; the main task of an indicator is to measure the situation to trigger the decision-making.

\section{Modeling and simulation}

A risk is a complex situation that needs to be managed. Banks are subject to undergo stress at this kind of event and must make decisions conveniently. One of the identified means is the use of modeling and simulation to analyze this problem.

The systemic [6] represents a particular approach which is adapted to understand the behavior of a complex system in order to model it to act and to simulate its variations in time.

A complex system, by definition, is a system that consists of many components, interconnections, interactions or interdependencies which are difficult to describe, understand, predict, manage, conceive, and change[7].

\subsection{The systemic approach}

The systemic approach is a means to understand the system and the organizational complexity. Its stages highlight two levels: the system which is constructed by an observer facing a complex situation [8] and the model which is the representation of a system. The purpose of its construction is to understand the degree of importance of the decision-making on the modeled system.

In this paper, we have relied on the work of Donnadieu and Karsky [9] who explain the systemic approach in five stages: observation, systemic exploration, qualitative modeling, dynamic modeling and simulation.

Several methods of modeling of processes [10] exist in literature, namely: the dynamics of the systems [11], the SADT [11], the FIS method[12] and the UML formalization[13].

The choice is based on the UML language: it describes the system, its functions, the resources, the hierarchy and schematically the process.

The UML approach will be used only to formalize the interactions within the system. For the dynamic modeling, we are based on the decision support systems (DSS).

Multi-agent systems (MAS)[14] constitute another way to implement tools for the decision-making. They consist in managing the agents by providing them with tasks for cooperation. 
Ansar Daghouri, Khalifa Mansouri, Mohammed Qbadou; Contribution to the Measurement of Organizational Performance based on A Multi-Agent Approach. Transactions on Machine Learning and Artificial Intelligence, Vol 5 No 4 August (2017); pp: 102-111

\subsection{Multi-agent systems (MAS)}

MAS are entities that interact with one another to produce a collective conduct. One of the main characteristics is the distribution of tasks on several agents that are objects capable of interacting and performing actions in parallel with other agents.

The agents must be coordinated with one another, which would allow to model the systems, the modes of communication and the simulations in the field. The interaction is essentially through the transfer of information which is broken down into three parts: receiving information, reasoning on other agents and issuing the messages or the actions to be performed.To build a MAS, there are several platforms[15]: Jade, MadKit, Zeus and Jack.

\section{Dss and the evaluation of organizational performance}

\subsection{Work methodology}

The proposed methodology to analyze the performance of banks' risk management unit is based on a systemic approach. This approach allowed us to analyze the system and model it to reduce its complexity. The proposed methodology provided a risk presentation to analyze the bank's weaknesses. This approach is based on five main axes:

Observation, to know the organization of the risk management unit and to identify its actors as well as the interactions between them;

Systemic exploration, which allows modeling the system studied and the different interactions between its components and the environment. For our case, modeling is done by the UML language;

The identification of performanceindicators, which will subsequently be integrated into the dynamic model for the analysis of the risk management unit;

Dynamic modeling, which adds the notion of time to the qualitative model. We have worked with MAS that have reduced the complexity of problem solving by dividing the tasks on agents;

Bank Evaluation: it allows having a general overview of the studied system in order to improve the performance of the bank.

This approach will make it possible to study, to model and to simulate the tasks of the risk unit to provide at the end a vision of a well-formalized decision support.

\subsection{The risk management unit}

The risk management approach in banks goes in parallel with the professional and the regulatory standards whose management rules are defined according to international levels which are recommended by the authorities. The Risk Management Unit is independent of business lines and professions and it reports directly to the Presidency. Its main task is to supervise and hedge the various risks which are inherent in the activities of the bank, and also to control and measure everything. 


\subsection{Risk modeling}

To understand the interaction between the actors in a risk management process, we propose a generic use case diagram(Fig.1):

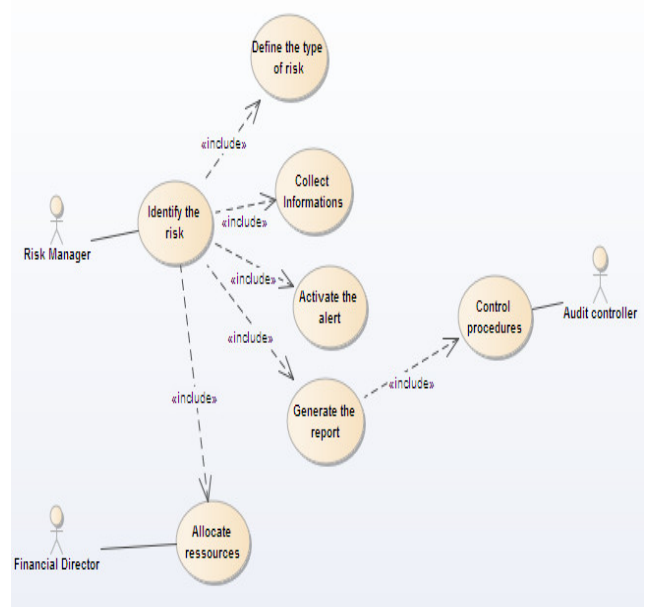

Figure.1. Risk Use Case Diagram

The risk management process begins when the Risk Manager identifies the risk, then it goes on to define the type of risk we have previously classified, the collection of information required for processing, internal rules and procedures, the triggering of the alert according to the type and severity of the risk, the preparation of a risk management report, which will be subsequently monitored by the audit controller, the request for the availability of financial resources from the financial management.

\subsection{Modeling of the risk management unit}

After identifying the actors of the unit and their roles, we have modeled the unit with the class diagram of the UML language.The unit consists of a set of committees, each of which is characterized by resources and interacting with each other.

We have worked on the most general case to arrive at a global bank model that is represented by the class diagram in Fig. 2.

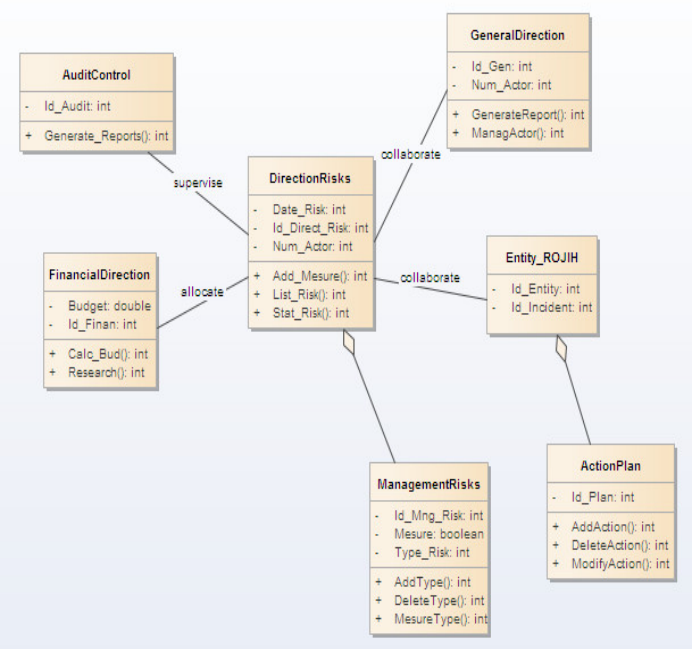

Figure.2: Unit class diagram 
Ansar Daghouri, Khalifa Mansouri, Mohammed Qbadou; Contribution to the Measurement of Organizational Performance based on A Multi-Agent Approach. Transactions on Machine Learning and Artificial Intelligence, Vol 5 No 4 August (2017); pp: 102-111

To model the risk management unit, it has been necessary to present all the departments that cooperate with the latter in order to better manage all the risks a bank can face. The class diagram consists of seven classes:

GeneralDirection : its objective is to monitor appropriate risk management policies, procedures and systems by collaborating with risk management;

DirectionRisks: it is responsible for setting up risk indicators and controlling each activity of the bank that may trigger a risk. It is therefore composed of a risk management department;

ManagementRisks : activates the overall risk management process involving the identification, definition, measurement and monitoring of all risks;

FinancialDirection :it checks the availability of the necessary financial resources for the management of the risk and subsequently it can allocate its resources to the risk management;

AuditControl : reviews internal procedures, assesses risk management tools and measures reliability and integrity to generate systematic and objective assessment reports;

EntityROJIH: attached to the direction risks, it is mainly concerned by operational, juridical IT and human risks;

ActionPlan: it identifies actions to reduce the impact of risks.

\subsection{Identification of performance indicators}

The choice of indicators is the most delicate step as it relates to the objectives of decision-makers. These indicators should monitor the organization's evolution, facilitate decision-making and improve performance. The selected indicators should be simple and representative. This choice was based mainly on the bibliography and the specific problems of this project. As a result, seven organizational performance indicators were identified:

Team Mobilization : this indicator enables to count the number of people present on each committee of the risk management unit since each committee is composed of a limited number of persons;

Means: identifies the means available at the time of risk. Each committee has its own means to intervene in risk management;

Duration: is the duration of mobilization of the unit actors. It generally equals one working day except for the cases of risk with very high degree;

Quality of information: when managing a risk, the key element is the information that will make the right decision at the right time. If the information circulates with difficulty or not entirely, the decision-maker will not be able to make the right decision;

The actors' competence: it allows knowing if all the actors are qualified and competent in the performance of their tasks. It is measured by the actors training within the bank. This is a central element used to increase their performance;

The group Cohesion: it relies on actors' motivation, shared emotions and interpersonal relationships; 
The actors Morale: it can be affected at risks and it will surely have repercussions on the performance of the bank since the psychic state of the actors has a strong influence on the management of risks.

\section{Elaboration of a prototype}

We propose a system that evaluates the risk unit by taking into account the performance indicators chosen beforehand. It is equipped with an SMA that allows simulating the different scenarios.

The developed prototype consists of three interconnected parts (Fig. 3):

The user interface that allows adding scenario details of a risk to analyze the results in the form of a dashboard;

Functional part that simulates the risk scenario. It is responsible for the collection and processing of information;

Last part which constitutes the database for storing the information necessary for the simulation.

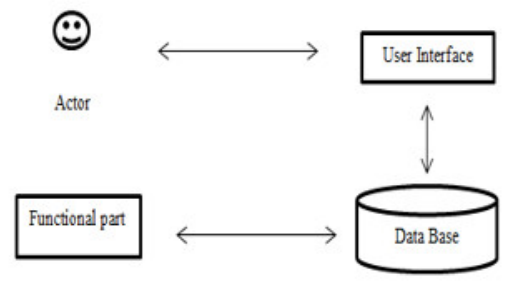

Figure. 3. Technical architecture

\subsection{The user interface}

The user interface is developed using the Java language under the Netbeans environment. It is connected to the database.After authentication through a login and a password, since it is the only one capable of simulating scenarios, the manager goes on to enter the data of the simulation.

\subsection{The functional part}

The role of this part is to detect the dysfunctions of the organization using the multi-agent systems according to a specific scenario. The system consists of a set of autonomous agents that each have separate threads and communicate with each other by sending messages. The MAS model of this system is represented by Fig. 4.

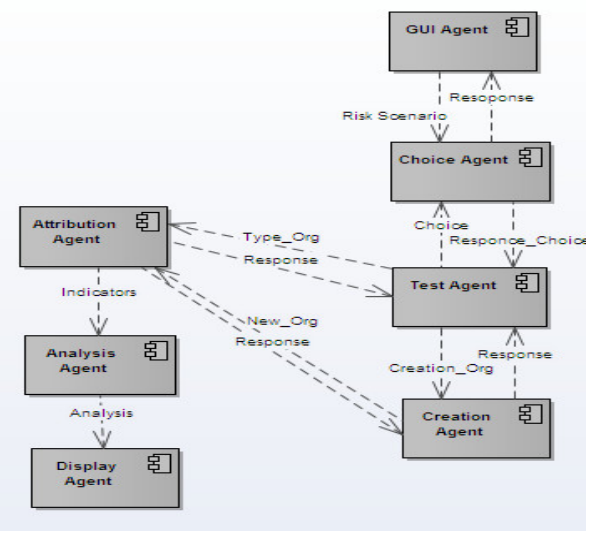

Figure .4. MAS structure of the proposed system 
Ansar Daghouri, Khalifa Mansouri, Mohammed Qbadou; Contribution to the Measurement of Organizational Performance based on A Multi-Agent Approach. Transactions on Machine Learning and Artificial Intelligence, Vol 5 No 4 August (2017); pp: 102-111

GUI Agent: which retrieves the specific information from the risk scenario via the user interface and seeks for a treatment from the choice agent;

Choice Agent: which allows the user to choose one unit organization among several according to the specificities and actors involved in risk management;

Test Agent: retrieves the user's opinion on whether he agrees on the type of organization or wants to add a new type;

Creation Agent: in case the user does not agree with the proposed organization, the agent proposes to him to define the type of the organization that suits him and is in charge of its creation;

Attribution Agent: which assigns to the actors of the chosen organization the value of the performance indicators which can be either 0 or 1 through a graphical interface;

Analysis Agent: Which is responsible for all the analyzes concerning the estimation of the duration of the simulation, the verification of the indicators and the study of the evolution of each indicator;

Display Agent: This displays the results of simulation.

\subsection{The database}

Data storage will be done using a database. We chose to work with SQL Lite because the recorded information is not large.

\section{Conclusion}

The aim of this paper was to propose a new approach for analyzing and evaluating the organizational performance of a risk management unit. The main idea is to simulate the process of risk management based on the systemic thinking and artificial intelligence. The result is a multi-agent system that integrates the performance indicators to simulate each type of risk within banks. The system proposed is being deployed and its uses will allow bank to improve their performance by analyzing the process of risk management and to change the internal structure.

\section{REFERENCES}

[1] P. A. Chiappori et M. O. Yanelle, «Le risque bancaire : un aperçu théorique,» Revue d'économie financière , pp. 97-111, 1996.

[2] O. De Bandt, P. Hartmann et J. L. Peydró, Systemic Risk in Banking, The Oxford Handbook of Banking, 2012.

[3] A. Mouhtadi, «Risque de liquidité : cas du Maroc,» International Journal of Innovation and Applied Studies, vol. 10 No, pp. 325-335, 2015.

[4] M. A. Malina et F. H. Selto, "Choice and change of measures in performance measurement models," Management Accounting Research, vol. 15, pp. 441-469, 2004.

[5] O. Villarmois, "Le concept de performance et sa mesure : un état de l'art, Les Cahiers de la Recherche, Centre Lillois d'Analyse et de Recherche sur l'Evolution des,» 2001. 
Transactions on Machine Learning and Artificial Intelligence Vol 5 No 4, Aug 2017

[6] M. Karsky, La dynamique des systèmes complexes ou la systémique de l'ingénieur, 2004.

[7] S. Sheard, "Complex Systems Science and its Effects on Systems Engineering," chez European Systems Engineering Conference, 2006.

[8] F. Le Gallou, «Systémique: Théorie et applications,» chez Editions Tec Et Doc, 1993.

[9] G. Donnadieu and M. Karsky, La systémique, penser et agir dans la complexité, Paris: Editions de liaisons, 2002.

[10] J. M. Flaus, E. Berthelier et F. Giannoccaro, «Modélisation de systemes organisationnels pour l'analyse des défaillances : application au plan de sauvegarde communal,» chez Conférence Internationale de Modélisation et Simulation, Tunisie, 2010.

[11] . G.-M. Karagiannis, thèse: Méthodologie pour l'analyse de robustesse des plans de secours industriels, 2010.

[12] J. Flaus , E. Berthelier et F. Giannoccaro, «Modélisation de systemes organisationnels pour l'analyse des défaillances : application au plan de sauvegarde communal,» 2010.

[13] J. Lin, L. Chaoyu Lin et S. Huang, «Improving System Performance by Extending Inheritance Analysis and Design,» 2016.

[14] M. Bienvenu, «Instructor for online course "Introduction to Artificial Intelligence" Institution: Université de Provence, Marseille, France,» 2006-2008.

[15] F. Bellifemine, A. Poggi and G. Rimassa, «JADE - A FIPAcompliant agent framework,» 1999. 